This is a postprint version of the following published document:

Yurdagul, E. (2017). Production complementarities and flexibility in a model of entrepreneurship. Journal of Monetary Economics, vol. 86, n. 4, pp. 36-51. Available in https://doi.org/10.1016/j.jmoneco.2017.01.002.

(C) Elsevier

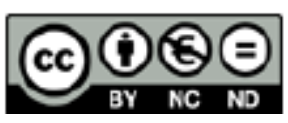

This work is licensed under a Creative Commons Attribution-NonCommercialNoDerivatives 4.0 International License. 


\title{
Production complementarities and flexibility in a model of entrepreneurship
}

\author{
Emircan Yurdagul \\ Dept. of Economics, Universidad Carlos III de Madrid, Calle Madrid, 126, Getafe, Spain
}

\section{A B S T R A C T}

The focus of this paper is the flexibility in working hours as a motive for entrepreneurship. The model exhibits inflexibilities for workers and entrepreneurs, which arise due to complementarities in production. In addition, it allows for volatile value of leisure to make flexibility in hours desirable. Differences in occupation specific flexibility, disciplined with the observed patterns in hours (level, persistence, dispersion) and income (persistence, dispersion), can explain relatively low income levels of entrepreneurs in the US and the occupation specific distributions of working hours and income. Policy relevance of the model features is discussed using experiments of workweek restrictions and income taxation.

\author{
Keywords: \\ Entrepreneurship \\ Labor supply \\ Production \\ Income distribution
}

\section{Introduction}

Factors affecting the selection into entrepreneurship determine the observed characteristics of firm owners, hence, change the productivity and output patterns of their firms (e.g. levels, volatility). Moreover, entrepreneurs are potential workers and this gives a direct link between entrepreneurship and the size of the labor force available for employment. Accordingly, identifying the motives for entrepreneurship and capturing the economic mechanisms underlying these motives are important for studying the firm level and aggregate productivity patterns, as well as the aggregate labor in the economy.

Standard macroeconomic theory on entrepreneurship treats the choice between salaried work and entrepreneurship mainly as a matter of productivity. In the seminal work by Lucas (1978), agents consider their relative ability of running a firm over being a worker and they become entrepreneurs if its pecuniary benefits are high enough. This model has been improved with features such as financial constraints and volatility in occupation specific ability to better match the patterns observed in the data including the wealth and income distribution (Buera and Shin, 2013; Cagetti and de Nardi, 2006; Midrigan and $\mathrm{Xu}, 2014)$.

Nevertheless, this line of research neglects the observed income differentials between entrepreneurs and workers. Hamilton (2000) shows that entrepreneurs generate less income than comparable workers. This is also true for any tenure in business, so that switching to salaried work at any time of entrepreneurship would make most business owners better off income wise. This feature in the data has brought attention to the non pecuniary benefits associated with entrepreneurship. For instance, Hurst and Pugsley (2011) use survey data on business owners to show that the majority of entrepreneurs list non pecuniary reasons such as flexible hours or preferring to be their own boss for starting their businesses. In another recent paper, Pugsley (2011) uses an innate preference for entrepreneurship to explain the observed income differentials.

E-mail address: eyurdagu@eco.uc3m.es 
Recognizing the role of non pecuniary motives in entrepreneurship is important, but a structural model that highlights the mechanisms accounting for such motives is still missing. In turn, this has prevented the literature from disciplining the explanations with the observed micro patterns other than the income differentials.

My objective in this paper is to fill this gap by focusing on the flexible hours motive for entrepreneurship, as this is one motive that can potentially be quantified using data on hours by workers and entrepreneurs. The empirical evidence provided here documents that the patterns of hours of entrepreneurs are different from those of workers. In the cross section, working hours are more disperse for entrepreneurs than they are for workers. The distribution of changes in hours are more concentrated around zero for workers than they are for entrepreneurs. Moreover, workers with hours close to the usual hours in their sectors tend to earn more per hour, which is a pattern that seems missing for entrepreneurs.

Departing from the highlighted facts, the question that follows is: Is the flexible hours motive, disciplined with the observed occupation specific patterns in hours (level, persistence, dispersion) and income (persistence, dispersion), strong enough to generate the observed differentials in income levels? In order to answer this question, I add two features to a standard entrepreneurship model. First feature is the shocks to the value of leisure in a fashion used in the literature in various contexts. ${ }^{1}$ Defining flexibility as the ability to change hours without sacrificing hourly income, volatile value of leisure creates a preference for flexibility. The second is a labor aggregation technology that exhibits complementarities between hours of workers. This novel feature makes workers more productive if their hours are similar to each other. Hence, it makes wages depend on the hours of work and get particularly low for those working too little or too much, consistently with the observed hump shaped pattern of workers' hourly income across their working hours. As a result of such an endogenous cost of deviating from the "usual" hours in the economy, the preference for flexibility manifests itself as a preference for entrepreneurship.

The Survey of Income and Program Participation (SIPP) is used to calibrate the model for the US. The model can generate the income differentials between workers and entrepreneurs. Moreover it gives a good fit for other untargeted moments such as income and hours distribution among entrepreneurs and workers.

In order to show the quantitative importance of the key features, I compare the model's performance with that of two standard alternatives that ignore worker complementarity and value of leisure volatility. The complete flexibility arising in the absence of complementarities creates a dispersion in workers' hours that is more than 50 percent larger than the data. The resulting lack of the flexibility motive for entrepreneurship generates counterfactually high average income for entrepreneurs. On the other hand, omitting the value of leisure shocks takes out an important source of hours variation from the model. The productivity shocks alone, calibrated to match the income dispersion for workers and entrepreneurs, can only generate half of the dispersion observed in hours for these occupations.

The benchmark economy has many workers finding it hard to keep up with the long hours of their peers. There are also individuals that have become entrepreneurs only to avoid the working hours that are too long for their value of leisure. Accordingly, policies leading to modest reductions in the working hours can help these people. This paper gives two examples, workweek restrictions and labor income taxation, to elaborate this quantitatively.

The inability of workers to choose their working hours without sacrificing hourly income has been documented empirically. Dickens and Lundberg (1993) use the Current Population Survey to show that 35 percent of male workers in the US would like to change their hours, and 28 percent would like to increase their hours given hourly wage. Stewart and Swaffield (1997) and Boheim and Taylor (2004) reach similar conclusions using datasets on UK workers. Altonji and Paxson (1988) show that there is a premium for working an undesirable amount of hours. They argue that firms have strong preferences for hours worked and that there is a fixed hours phenomenon. Aaronson and French (2004) use the social security rules in the US to identify the link between hours and hourly wage. They find that there is a significant wage penalty for switching to part time work from full time work for men. Moreover, they argue that the models ignoring the nonlinear link between hours and wages are bound to underestimate the effects of income taxation on labor supply. Rogerson (2011) surveys the literature documenting the inflexibilities in labor supply, as well as the studies that exogenously introduce these inflexibilities to a standard labor supply model. He also extends a standard model by an exogenously given non linear wage rate. The way inflexibilities in hours arise here is close to this feature of Rogerson (2011). Importantly, my model presents an underlying mechanism to generate the non linear wage scheme.

The paper is organized as follows. Section 2 provides evidence from the US suggesting that volatile preferences and inflexible hours can be playing a role in individuals' decision of entrepreneurship. Section 3 introduces the benchmark model. Section 4 explains the calibration and Section 5 presents the main results. Section 6 discusses the role of the main features of the benchmark model and their relevance for policy. Section 7 concludes.

\footnotetext{
${ }^{1}$ For instance, Erosa et al. (2016) show that such heterogeneities in the value of leisure are key in understanding the labor supply elasticities of workers. Aaronson and French (2004) also use value of leisure shocks to capture the observed variations for workers.
} 
Panel A: Income and hours
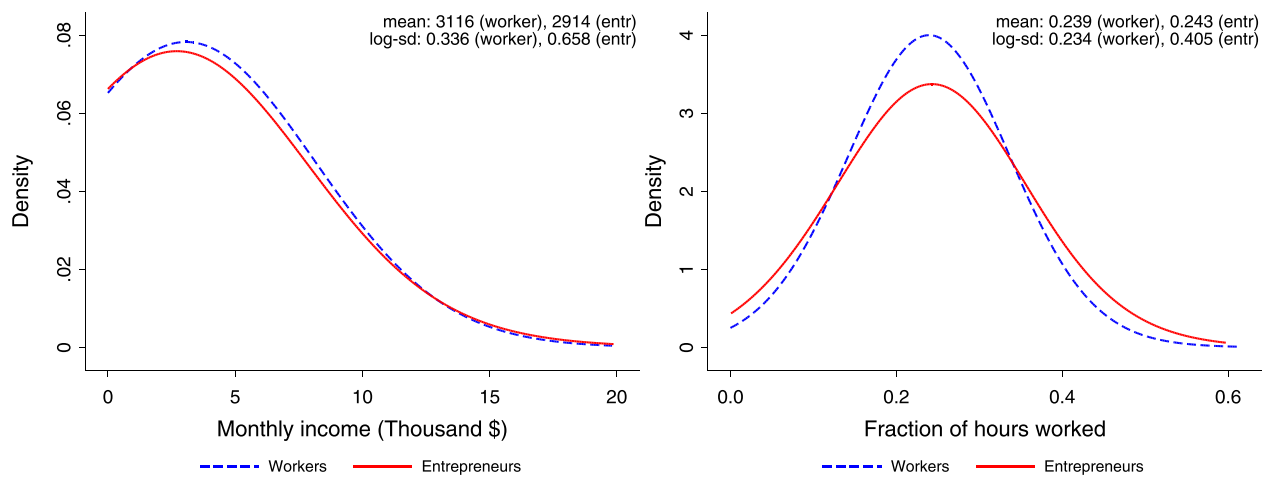

Panel B: Changes in hours and residual hours controlled by hourly income
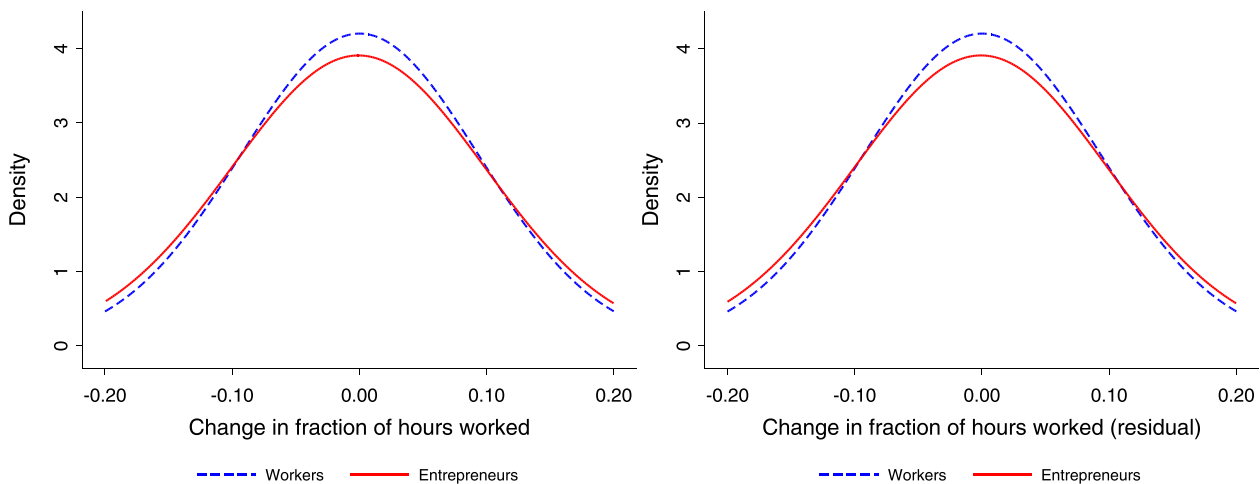

Fig. 1. Distribution of income, hours, changes in hours (data). Note: Hours and hourly income are conditional on sex, race, disability, education, potential job experience, year dummies and the interactions between these variables. (This is also true for the rest of the figures.)

\section{Empirical evidence}

The objective of this section is to use the SIPP to clarify the motivation of the paper. The SIPP provides micro level panel data, with an interval of four months between waves and with around ten waves within each panel. In addition to standard characteristics such as sex, race, disability and education, it collects information about occupation, hours, and income.

In order to condition out the factors that are not features of my model, I first regress hours and hourly income on sex, race, disability, education, potential job experience, year dummies and the interactions between these variables. Then the residuals are adjusted to have the minimum in the sample equal to 0 and the mean equal to that of the corresponding dependent variable. This gives the measures of conditional hours and hourly income (hence the total income) that will be used for the rest of the paper.

For business owners, the SIPP includes information on the size category of the firm, where these categories are 024,25 99 and $100+$. My sample excludes entrepreneurs in the largest category for two reasons. A focus here is hours worked by entrepreneurs. Meanwhile, at the top of the firm size distribution, the ownership structure of a firm gets less clear, hence the weight of the entrepreneurial input in the production technology would differ. Moreover, the returns to scale that these very large firms exhibit would be larger than the smaller ones. ${ }^{2}$ The Online Appendix provides further details on the data and the summary statistics for the sample.

Panel A of Fig. 1 shows the distribution of income and hours separately for entrepreneurs and workers. The income of entrepreneurs is more disperse than that of workers. Entrepreneurs in the sample earn less than workers on average. Hours worked by the two occupational groups also exhibit different patterns. To begin with, an average entrepreneur works more than an average worker. Similar to their income, entrepreneurs' working hours also vary more in the cross section and have fatter tails than workers' hours.

Working hours in the two occupations are different also in volatility. Panel B of Fig. 1 first depicts the changes in hours worked by people who have the same occupation in two consecutive periods. The hours by entrepreneurs are more volatile.

\footnotetext{
${ }^{2}$ The quantitative analysis in this paper revisits this discussion with the estimation of the span-of-control for the firms in the data. Another note is that the probability of an entrepreneur that employs less than or equal to 99 to employ more than that next period conditional on continuing to be an entrepreneur is 0.31 percent. The probability of the switch in the other direction is 21 percent.
} 
Interestingly, the patterns in levels and differences of hours are the same if we look at hours, once controlled by the hourly income, as the second figure in Panel B documents. ${ }^{3}$

One candidate mechanism making the working hours less volatile and more concentrated around the mean for workers would be complementarities between their hours. In particular, if complementarities between hours of workers in a pro duction unit are stronger than those between workers and their employers, the hourly premium for working usual hours will be higher for workers. While we do not observe the distribution of hours and wages within the production units of workers, the SIPP provides information on their detailed sectors and education levels. If the skills of workers (measured by education) proxy their production units, and the distributions of hours and wages within each sector resemble those within a typical unit it has, the hours wages relationship within sectors for different education groups can be informative in the presence of complementarities in labor aggregation.

The next exercise splits the sample into two education groups and shows that within each sector (i) the wages of workers peak at the hours close to what an average worker works, and decrease towards extremely high and low working hours, (ii) these patterns contrast with the much more monotone hours hourly income relationship of entrepreneurs. ${ }^{4}$ Education groups divide the sample as individuals with and without a college degree. In order to illustrate the hours wages rela tionship for each group in a simple figure while controlling for the differences between sectors, Panel A of Fig. 2 plots the difference between workers' hourly income and the average in their sector $\left(w_{i j} \bar{w}_{j}\right.$, where $i$ denotes a worker, $j$ is her sector and hourly incomes are normalized to have average among all workers equal to unity) against the difference between their working hours and the average in the sector $\left(l_{i j} \bar{l}_{j}\right)$. The figure shows that hourly income relative to a worker's sector indeed peaks close to the usual hours, and decreases monotonically with the distance from the wage maximizing hours.

An alternative way of looking into the same pattern is to do a similar exercise for each sector separately. For this purpose, Panel B of Fig. 2 groups the detailed sectors for workers into fewer categories. There are different ways of doing this categorization, and the strategy here is to follow the industry grouping available in the SIPP for entrepreneurs in order to allow comparison later on. The figure shows hourly income across deviations from the hours of the mean worker in every industry category. For each of these 12 categories, there is a hump shaped pattern in the hourly income for workers from both educational groups.

Panel B of Fig. 2 also documents that the patterns for entrepreneurs are quite different from those for workers. In particular, their hourly income typically does not exhibit a peak in intermediary ranges of working hours spectrum. Instead, entrepreneurs' hourly income follows a monotone pattern, either increasing or decreasing, with respect to their hours for most sectors and education groups. ${ }^{5}$

Certainly, the take away from this exercise is not that entrepreneurs are not complementary to their workers, or that they are more flexible. Instead, Fig. 2 suggests that complementarities between workers can be different from those between entrepreneurs and workers. In turn, the flexibilities permitted by the aggregation technologies in production can potentially be different for workers than entrepreneurs. ${ }^{6}$

In order to quantify further the differences in the volatility of hours by the two occupational groups, I next run simple OLS regressions with the absolute changes in hours as the dependent variable in a sample of people that keep their occupation between two consecutive waves. As shown in Table 1, only including the dummy variable for entrepreneurship gives significantly positive effects on the absolute changes in hours. This also holds when the characteristics used earlier to get the conditional measures of hours and hourly income are included in the estimations. As the distributional differences between the changes of working hours before and after controlling for hourly income are minimal (Panel B of Fig. 1), it is useful to repeat the estimations in column 2, by also conditioning on the changes in the hourly income, to see that the driving force in the changes in working hours is not only the changes in productivity. Column 3 shows that the larger differences for entrepreneurs are robust to controlling for the changes in productivity. ${ }^{7}$ This suggests that there is some other mechanism leading to differences in hours that does not have much to do with pecuniary returns to working.

An important factor in the observed changes in hours can be shocks to the value of leisure. Correspondingly, it is worthwhile to come up with some measures in the data to capture these shocks to see (i) how significantly they change the hours worked by people, and in turn (ii) how big of a role they play in switches to entrepreneurship. Next, two different variables are introduced to proxy the arrival of shocks on the value of leisure: absolute changes in the family size and a change in the marital status.

\footnotetext{
${ }^{3}$ A Kolmogorov-Smirnov (KS) test rejects the null hypothesis that the distribution for entrepreneurs is the same with that workers at the 1 percent level for all comparisons in Fig. 1. To be specific, the implied $D$-statistic is 0.24 for the distributions of income, and 0.18 for the hours. It is 0.14 for the distribution of changes in hours and 0.13 for that of the residual hours.

${ }^{4}$ I would like to thank the referee for encouraging me to perform this exercise.

5 The Online Appendix shows that the findings are similar if we repeat the exercises depicted in Fig. 2 for the entire sample instead of conditioning on educational status.

${ }^{6}$ Clearly, Fig. 2 can be explained by alternative theories. One explanation can be that the unobserved ability is lower for workers with extreme hours. However, it would require a non-trivial argument to generate (i) hump-shaped relationship in ability and observed working hours for workers, (ii) observed differences between workers and entrepreneurs, with unobserved ability levels.

${ }^{7}$ Focusing on people that are workers or entrepreneurs for two consecutive periods can create a sample selection issue, as job-stayers are more likely to be receiving positive occupation specific shocks. Running these regressions separately for negative and positive changes in hours, in order to mitigate the selection issue give similar results. Moreover, controlling for the job categories also makes little difference.
} 
Panel A: Hourly income and hours in difference to subsector mean (workers)

a

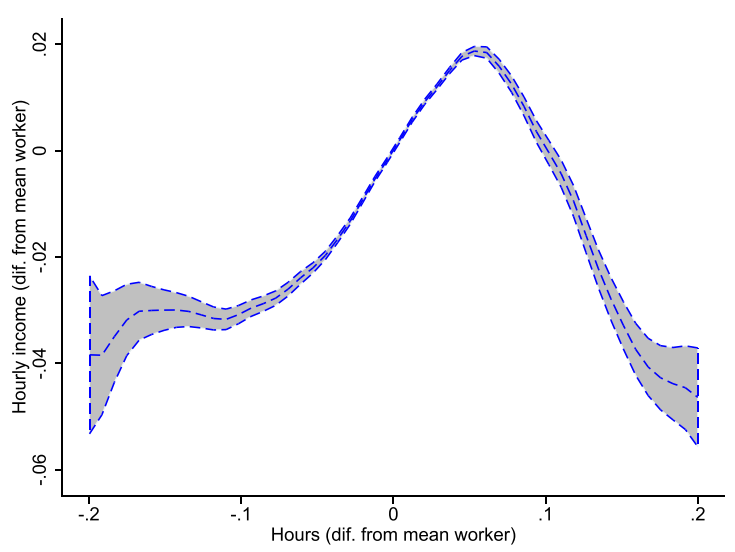

b High education

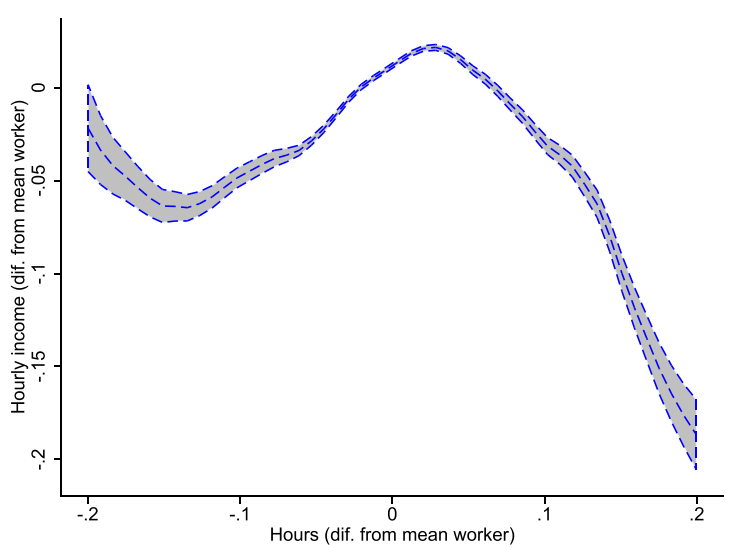

Panel B: Hourly income and hours across sectors

a

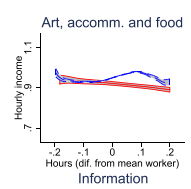

Hours (diff. from mean worker)
Information

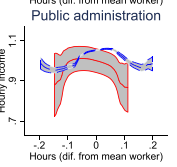

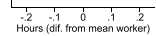

Low education
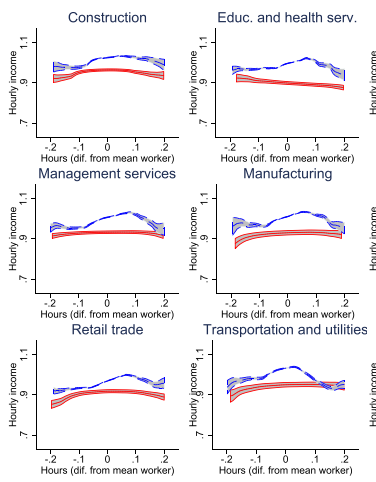

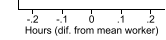

Entrepreneurs

[---] Workers

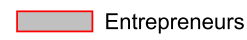

b
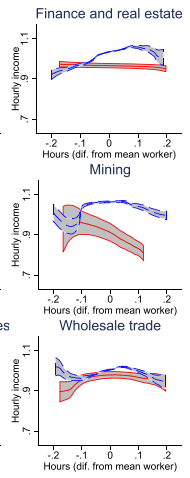
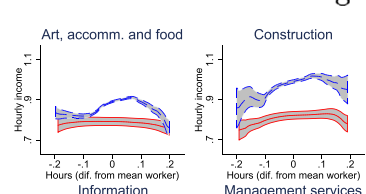

High education
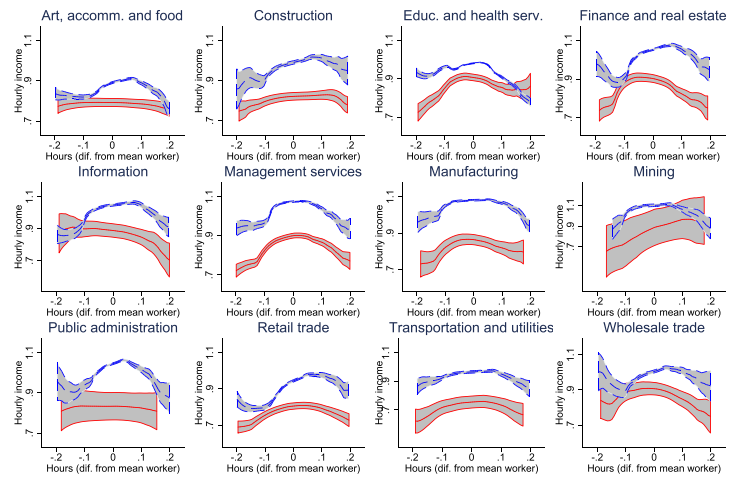

[--- Workers

Entrepreneurs

Fig. 2. Working hours and wages within each sector. Note: Figures in Panel A plot the Kernel-weighted local polynomial smoothing of hourly income against the levels of hours (both differences from sector mean). Figures in Panel B plot that of hourly income across the levels of difference in hours from the mean worker in each sector. Plotted around the curves are the confidence intervals at 95 percent level. The initial levels of hourly income are normalized to have an overall average of 1 for workers. Figure (a) uses individuals without a college degree and (b) uses college degrees and above.

Changes in the family size can capture the arrival of a child, which would have an impact on the value of leisure of the parents. It can also indicate the death of a family member, hence the presence of an individual in the family with critical health condition between two waves requiring time allocated for health care. Changes in the marital status can account for the changes in the value of leisure in the first few months in a new marriage or in the adjustment period to the single life. In order to see if these variables have explanatory power on the changes in hours, the OLS estimations in Table 1 with changes in hours as the dependent variable continue by including the changes in the family demographics as independent variables. Column 4 adds the absolute change in the family size as the independent variable, and shows that the coefficient for this variable is positive and significant. Column 5 does the same for the change of the marital status and obtains qualitatively similar results. Finally, column 6 uses both proxy variables for the preference shocks in the same estimation. Notice that the coefficients for both variables are significantly positive.

According to the mechanism pursued here, variables necessitating a change in the hours worked would make flexible hours hence entrepreneurship more desirable. In order to see the plausibility of this logic, I regress the switch to entrepreneurship on the previous proxies for the shocks on the value of leisure. These estimations also include the char acteristics as in the previous tables, as well as the lagged hourly income in order to control for possible productivity shocks workers might receive. Columns 1 and 2 of Table 2 show that the absolute changes in the family size and in the marital status have significant positive effects on switches to entrepreneurship when they are included separately in the 
Table 1

Estimation of change in hours worked.

\begin{tabular}{|c|c|c|c|c|c|c|}
\hline \multirow[t]{2}{*}{ Variables } & \multicolumn{6}{|c|}{ Dependent variable: Absolute change in fraction of hours worked } \\
\hline & (1) & $(2)$ & (3) & (4) & (5) & (6) \\
\hline Entrepreneur & $\begin{array}{l}0.0190^{\text {***** }} \\
(158.3)\end{array}$ & $\begin{array}{l}0.0185^{* * * *} \\
(153.3)\end{array}$ & $\begin{array}{l}0.0175^{\text {***** }} \\
(146.9)\end{array}$ & $\begin{array}{l}0.0176^{\text {***** }} \\
(147.0)\end{array}$ & $\begin{array}{l}0.0175^{\text {***** }} \\
(146.8)\end{array}$ & $\begin{array}{l}0.0176^{\text {**** }} \\
(147.0)\end{array}$ \\
\hline Hourly income ch. & & & & & & $0.000388^{* * * * *}$ \\
\hline $0.000387^{* * * *}$ & & & & & & 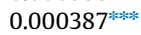 \\
\hline \multicolumn{7}{|l|}{$0.000387^{* * * *}$} \\
\hline & & & $(167.1)$ & $(166.9)$ & $(167.0)$ & $(166.9)$ \\
\hline Ch. in family size & & & & $\begin{array}{l}0.00254^{\text {*k*k*k }} \\
(32.15)\end{array}$ & & $\begin{array}{l}0.00229^{* * * * *} \\
(27.54)\end{array}$ \\
\hline Ch. in marital status & & & & & $\begin{array}{l}0.00563^{* * * *} \\
(19.10)\end{array}$ & $\begin{array}{l}0.00294^{* * * * *} \\
(9.476)\end{array}$ \\
\hline Characteristics & No & Yes & Yes & Yes & Yes & Yes \\
\hline Constant & $0.0177^{* * * *}$ & -0.00837 & -0.00585 & -0.00670 & -0.00611 & -0.00675 \\
\hline & $(502.9)$ & $(-0.491)$ & $(-0.348)$ & $(-0.399)$ & $(-0.363)$ & $(-0.402)$ \\
\hline Observations & $1,008,003$ & $1,008,003$ & $1,008,003$ & $1,007,767$ & $1,007,767$ & $1,007,767$ \\
\hline$R^{2}$ & 0.024 & 0.038 & 0.064 & 0.065 & 0.064 & 0.065 \\
\hline
\end{tabular}

Note: The sample consists of individuals that keep being an entrepreneur or being a worker since the previous wave. Except the estimation in (1), explanatory variables also include sex, race, disability, education, potential job experience, year dummies and the interactions between these variables. Hourly income change is the absolute change in the ratio of monthly income to usual hours worked. The change in the family size is absolute change in the number of persons in the family relative to previous period. The change in the marital status is the absolute change in the marriage indicator.

$t$-Statistics in parentheses.

${ }^{* * *}$ indicate significance at 1 percent level.

regressions. $^{8}$ Column 3 shows that the effects of the two proxies are also significantly positive if they are both included as explanatory variables in the regression. Finally, including a dummy variable for having an entrepreneurship experience in the previous waves does not reduce the significance of the demographic variables.

Though not conclusive, evidence in this section supports the findings in the literature in three ways. First, a typical entrepreneur earns less than a typical worker. Second, entrepreneurs work more on average. Third, workers' hours are not as disperse as they are for entrepreneurs, and they do not move as much between periods, which potentially hints that workers are more constrained in hours. In fact, different from entrepreneurs, the hourly income of workers seem to exhibit a premium to working close to usual hours in a sector. Finally, the changes in the value of leisure, proxied by the changes in the household demographics, have significant explanatory power in changes in hours and in switches to entrepreneurship.

The next section introduces the model, which presents a realistic modification of a standard entrepreneurship model in order to account for the facts illustrated above.

\section{Model}

The description of the setting starts from the production technology of the firms, and then goes over the details of the household side of the economy.

\subsection{Firms}

Production of all the firms in the economy can be represented by $Y_{m}=Z_{m}\left(K_{m}^{\alpha} L_{m}^{1-\alpha}\right)^{\tilde{\eta}_{m}}$, where $m$ is the index of the firm, $K_{m}$ denotes capital, $L_{m}$ is the effective external labor and $Z_{m}$ is the efficiency of these two factors. $\tilde{\eta}_{m}$ governs the returns to scale in the production and it is potentially different across firms. Effective labor of a firm is an aggregation across units consisting of workers with different skill levels, $L_{m}=\int_{0}^{\infty} y L_{m}(y) d y$, where $L_{m}(y)$ denotes the aggregate hours of work by skill group $y$ at firm $m$. In the aggregation technology, there are potential complementarities between hours of workers:

$$
L_{m}(y)=\left(\int_{i \in N_{m}(y)} l_{i}^{\rho} d i\right)^{\frac{1}{\rho}}\left(\int_{i \in N_{m}(y)} 1 d i\right)^{1-\frac{1}{\rho}},
$$

\footnotetext{
${ }^{8}$ Instead of the magnitude of the change, using the indicator of a change in the family size or using increases and decreases separately make little difference. Moreover, introducing all the interactions between the characteristics used in these estimations does not make a big difference, neither in the explanatory power of the model nor in the significance of the independent variable of interest. Omitting the previous hourly income and the characteristics in these estimations do not give very different results in terms of the coefficients of the demographic variables, but reduce $R^{2}$ of these estimations.
} 
Table 2

Estimation of switching to entrepreneurship, using changes in demographics.

\begin{tabular}{|c|c|c|c|c|}
\hline \multirow[t]{2}{*}{ Variables } & \multicolumn{4}{|c|}{ Dependent variable: Indicator of becoming an entrepreneur } \\
\hline & $(1)$ & $(2)$ & (3) & $(4)$ \\
\hline Change in family size & $\begin{array}{l}0.00428^{\text {***** }} \\
(23.46)\end{array}$ & & $\begin{array}{l}0.00353^{* * * *} \\
(18.37)\end{array}$ & $\begin{array}{l}0.00354^{\text {***** }} \\
(18.48)\end{array}$ \\
\hline Change in marital status & & $\begin{array}{l}0.0129^{\text {***** }} \\
(19.06)\end{array}$ & $\begin{array}{l}0.00877^{* * * *} \\
(12.27)\end{array}$ & $\begin{array}{l}0.00872^{\text {*k** }} \\
(12.26)\end{array}$ \\
\hline Entr, hist & & & & $\begin{array}{l}0.0397^{* * * *} \\
(89.82)\end{array}$ \\
\hline Constant & $\begin{array}{l}0.123^{* * * *} \\
(3.352)\end{array}$ & $\begin{array}{l}0.124^{* * * *} \\
(3.375)\end{array}$ & $\begin{array}{l}0.123^{* * * * *} \\
(3.347)\end{array}$ & $\begin{array}{l}0.124^{* * * *} \\
(3.384)\end{array}$ \\
\hline Observations & 927,367 & 927,367 & 927,367 & 927,367 \\
\hline$R^{2}$ & 0.009 & 0.008 & 0.009 & 0.017 \\
\hline
\end{tabular}

Note: The sample consists of individuals that were workers in the previous period. For the estimations, linear probability model is used. Dependent variable is the indicator of becoming an entrepreneur. Characteristics that are controlled for are sex, race, disability, education, potential job experience, year dummies and the interactions between these variables. Current and previous hourly income level is also included among the controls. The change in the family size is absolute change in the number of persons in the family relative to previous period. The change in the marital status is the absolute change in the marriage indicator.

$t$-Statistics in parentheses.

${ }^{* * *}$ indicate significance at 1 percent level.

where $N_{m}(y)$ is the set of workers with skill $y$ at firm $m$, and $\left\{l_{i}\right\}_{i \in N_{m}(y)}$ is their hours worked. In order to abstract from indices of workers, one can rewrite the aggregation in terms of measure of workers employed with each level of hours worked:

$$
\left.L_{m}(y)=\int_{0}^{1} \mu_{m}(l, y) l^{\rho} d l\right)^{\frac{1}{\rho}}\left(\int_{0}^{1} \mu_{m}(l, y) d l\right)^{1-\frac{1}{\rho}},
$$

where $\mu_{m}(l, y)$ is the measure of workers with skill $y$, working $l$ hours for firm $m$.

\subsection{Consumers}

There is a continuum of infinitely living agents with unit mass. Preferences are given by:

$$
\sum_{t}^{\infty} \beta^{t}\left[\frac{c_{i t}^{1-\gamma}}{1 \gamma} \quad v_{i t} \frac{l_{i t}^{1+\phi}}{1+\phi}\right] .
$$

For all individuals, the value of leisure evolves with the process ${ }^{9}$ :

$$
\log v_{i t}=\left(\begin{array}{ll}
1 & \pi_{v}
\end{array}\right) \log \left(v_{0}\right)+\pi_{v} \log v_{i t-1}+\xi_{i t}, \quad \xi_{i t} \sim N\left(0, \sigma_{v}\right) .
$$

An individual can be a worker or an entrepreneur. Entrepreneurial ability, $A_{i t}$, follows:

$$
\log A_{i t}=\left(\begin{array}{ll}
1 & \pi_{A}
\end{array}\right) \log A_{0}+\pi_{A} \log A_{i t-1}+\zeta_{i t}, \quad \zeta_{i t} \sim N\left(0, \sigma_{A}\right) .
$$

Skill level of a worker also evolves stochastically with process:

$$
\log y_{i t}=\pi_{y} \log y_{i t-1}+\epsilon_{i t}, \quad \epsilon_{i t} \sim N\left(0, \sigma_{y}\right),
$$

and variables $\xi_{i t}, \zeta_{i t}$ and $\epsilon_{i t}$ are drawn independently from each other.

Any individual in the economy can become a worker at any time. However workers are free to start their businesses only with probability $s \in(0,1]$. This assumption captures the stochastic nature of the arrival of opportunities for entrepreneurship.

Consumers pay income taxes at a flat rate $\tau$, and receive lump sum transfers $T$. Taxable income consists of labor earnings and interests earned on risk free bonds. ${ }^{10}$

Consumers' problem: The value function of an individual with wealth $a$, ability levels $A$ and $y$, and the disutility variable $v$, if she can freely choose the occupation this period, is

$$
V(a, A, y, v)=\max \left\{V^{e}(a, A, y, v), V^{w}(a, A, y, v)\right\},
$$

where $V^{e}$ is the value of being an entrepreneur and $V^{w}$ is the value of being a worker. Entrepreneurs choose their savings, $a^{\prime}$; consumption, $c$; supply of labor to their firms, $h$; the capital to be rented for their firms, $K$; and measure of workers with skill

\footnotetext{
${ }^{9}$ The Online Appendix includes an extension that allows for heterogeneities in the value of leisure volatility.

${ }^{10}$ The Online Appendix discusses the reasoning behind the assumption of a flat rate and the implications of using progressive taxation instead of the flat tax rate in the main computations of the paper.
} 
level $y$ to work $l$ hours. The value function of an entrepreneur is:

$$
\begin{aligned}
& V^{e}(a, A, y, v)=\max _{c, h, a^{\prime}, K, \mu(l, y)} \frac{c^{1-\gamma}}{1} \gamma \quad v \frac{h^{1+\phi}}{1+\phi}+\beta E\left[V\left(a^{\prime}, A^{\prime}, y^{\prime}, v^{\prime}\right) \mid A, y, v\right] \\
& \text { s.t. } \quad c+a^{\prime}=\Pi+a(1+r) \quad \tau(\Pi+a r)+T \\
& \Pi=Y \quad K(r+\delta) \quad \int_{0}^{\infty} \int_{0}^{1} w(l, y) \mu(l, y) l d l d y \\
& Y=A h^{\omega}\left(K^{\alpha}\left[\left(\int_{0}^{1} \mu(l, y) l^{\rho} d l\right)^{\frac{1}{\rho}}\left(\int_{0}^{1} \mu(l, y) d l\right)^{1-\frac{1}{\rho}}\right]^{1-\alpha}\right)^{\eta} \\
& c \geq 0, \quad h \in[0,1], \quad a^{\prime} \geq 0, \quad K \geq 0, \quad \mu(l, y) \geq 0 \quad \forall l \in[0,1] .
\end{aligned}
$$

Workers make decisions on their savings and labor supply. Their value function is:

$$
\begin{aligned}
& V^{w}(a, A, y, v)=\max _{c, l, a^{\prime}} \frac{c^{1-\gamma}}{1} \gamma v \frac{l^{1+\phi}}{1+\phi}+\beta E\left[s V\left(a^{\prime}, A^{\prime}, y^{\prime}, v^{\prime}\right)+(1 \quad s) V^{w}\left(a^{\prime}, A^{\prime}, y^{\prime}, v^{\prime}\right) \mid A, y, v\right] \\
& \text { s.t.c }+a^{\prime}=w(l, y) l+a(1+r) \quad \tau(w(l, y) l+a r)+T \\
& c \geq 0, \quad l \in[0,1], \quad a^{\prime} \geq 0 .
\end{aligned}
$$

The value of the consumer that was a worker last period and did not receive a business opportunity this period is simply $V^{w}(a, A, y, v)$.

The optimal consumption, assets and labor supply if the consumer has the opportunity to be an entrepreneur (keep being an entrepreneur or switch to become one) are $c_{0}(a, A, y, v), a_{0}(a, A, y, v)$ and $l_{0}(a, A, y, v)$, respectively. If the consumer has to be a worker, the policy functions are $c_{N}(a, A, y, v), a_{N}(a, A, y, v)$ and $l_{N}(a, A, y, v)$. The indicator of choosing entrepre neurship over being a worker in case of having an opportunity is $S(a, A, y, v)$. Policies for capital and the labor measure for entrepreneurs are $K_{n}(a, A, y, v)$ and $\mu_{n}(l, y ; a, A, y, v)$.

Non entrepreneurial sector's problem: Non entrepreneurial firms' problem is static. They choose how much capital to rent, $K$; the measure of workers with skill level $y$ to work $l$ hours; and their total output, $Y$. To be specific, their maximization problem reads:

$$
\begin{aligned}
& \max _{K, \mu} Y \quad(r+\delta) K \quad \int_{0}^{\infty} \int_{0}^{1} w(l, y) \mu(l, y) l d l d y \\
& \text { s.t. } Y=B K^{\alpha}\left[\left(\int_{0}^{1} \mu(l, y) l^{\rho} d l\right)^{\frac{1}{\rho}}\left(\int_{0}^{1} \mu(l, y) d l\right)^{1-\frac{1}{\rho}}\right]^{1-\alpha} .
\end{aligned}
$$

The optimal capital and the measure of labor are denoted by $K_{b}$ and $\mu_{b}(l, y)$, respectively.

Stationary equilibrium: A stationary equilibrium is an allocation $K_{b}, \mu_{b}(l, y), K_{n}(a, A, y, v), \mu_{n}(l, y ; a, A, y, v), c_{i}(a, A, y, v)$, $a_{i}(a, A, y, v), l_{i}(a, A, y, v)$ for $i \in\{N, O\}, S(a, A, y, v)$, prices $r, w(l, y)$, and time invariant distribution $\varphi(a, A, v, J)$ over wealth $(a)$, entrepreneurial productivity $(A)$, worker skill $(y)$, value of leisure $(v)$ and occupation $(J)$ such that:

(i) Policy functions solve the problems of consumers.

(ii) $K_{b}$ and $\mu_{b}$ solve the problem of the non entrepreneurial sector.

(iii) Asset markets clear. The total capital used by the non entrepreneurial sector and the entrepreneurial sector is equal to the total wealth in the economy.

(iv) Labor markets clear. Total measure of workers demanded by all firms for each level of productivity $y$ and working hours $l \in[0,1]$ is equal to the corresponding labor supply.

(v) Government budget is balanced. Total tax revenues equal total lump sum transfers.

Discussion on flexibility in salaried work: The model does not allow a fully analytical characterization of the equilibrium. Nevertheless, one can derive the equations for wages to illustrate a worker's trade off between wages and hours. While the solution of firms' profit maximization problem is left to the Online Appendix, an important implication of this solution is that the wages depend on hours of work. In particular, equilibrium wages satisfy:

$$
w(l, y)=\left(\begin{array}{ll}
1 & \alpha
\end{array}\right)\left(\frac{\alpha}{r+\delta}\right)^{-\frac{\alpha}{1-\alpha}} y E_{\bar{x}, y}\left(l^{\rho}\right)^{\frac{1}{\rho}}\left[\frac{1}{\rho} \frac{l^{\rho-1}}{E_{\bar{x}, y}\left(l^{\rho}\right)}+\left(\begin{array}{ll}
1 & \frac{1}{\rho}
\end{array}\right) l^{-1}\right]
$$


where

$$
E_{\bar{x}, y}\left(l^{\rho}\right)=\frac{\int_{0}^{1} \bar{x}(l, y) l^{\rho} d l}{\int_{0}^{1} \bar{x}(l, y) d l}, \quad \bar{x}(l, y) \equiv \int_{n \in \mathbf{M}_{A}} \mu_{n}(l, y) d n+\int_{b \in \mathbf{M}_{B}} \mu_{b}(l, y) d b,
$$

and $\mathbf{M}_{A}$ and $\mathbf{M}_{B}$ denote the set of entrepreneurial and non entrepreneurial firms in the economy, respectively. Eq. (15) shows that a worker's wage depends on her hours of work relative to fellow workers with the same skill level. The max imum hourly wage is achieved at $l^{*}(y)=E_{\bar{x}, y}\left(l^{\rho}\right)^{\frac{1}{\rho}}$. Wages decrease as working hours get further away from $l^{*}(y)$.

I return to this discussion once calibrating the model, and highlight these inflexibilities showing how the hourly incomes change with working hours in the simulated economy.

\section{Calibration}

In SIPP, the relevant information is updated only with each wave, hence one period in my model corresponds to four months. Accordingly, following Cagetti and de Nardi (2006), who take the yearly depreciation rate equal to $0.06, \delta$ is set to 0.02 . The calibration follows the same paper in assuming $\alpha=0.33, B=1$ and $\gamma=1.5$. The discount rate $\beta$ is assumed to be equal to 0.983 corresponding to a yearly discount factor of 0.95 .

There is extensive literature estimating the elasticity of labor supply, which here is the inverse of the parameter $\phi$, with substantial differences in studies focusing on aggregates and those working on micro surveys. Here, $\phi$ is set equal to 2 , a value consistent with micro estimates of labor supply elasticity.

The span of control parameter for the entrepreneurial production function, $\eta$, is chosen to have the total income of external labor in the entrepreneurial sector relative to the income of entrepreneurs equal to the one in the data. The SIPP asks respondent about the number of workers employed by one's employer at all locations, while the answer has to fall into categories 0 24, 2599 or larger. The ratio of interest is that of the total income by the workers in the first two categories to the total income of entrepreneurs, which in this paper corresponds to employers of 99 or less. The relative income share of workers in the entrepreneurial sector implied by the model is $\frac{(1-\alpha) \eta}{1-\eta}$. Equating two ratios gives $\eta=0.504$. This value is much lower than the standard range, which is around 0.85 . The difference is due to excluding the entrepreneurs with large businesses. Doing the same derivations in the sample that includes these big businesses gives the span of control parameter equal to $0.94 .^{11}$ This is consistent with having the non entrepreneurial sector separately in the model, with a production function exhibiting constant returns to scale.

I approximate the stochastic processes in the model using Rouwenhorst method outlined by Kopecky and Suen (2010). There are five grid points for the value of leisure, three points for entrepreneurial ability and two grid points for the ability as workers. The autocorrelation of worker ability is assumed to be equal to 0.983 , again following Cagetti and de Nardi (2006).

The sample here excludes unemployment spells, owners of big businesses, and focuses on income conditional on observable characteristics such as education. Hence, using the tax rate corresponding to the median individual for the entire population is a natural choice in the context of this paper. Using Internal Revenue Service data from 2000, Guner et al. (2014) estimate the average Federal tax rate to be 7 percent for the middle income quantile in the US. They also estimate the total of state and local taxes to be at 4 percent for this quantile. Accordingly, $\tau$ is set equal to 11 percent. The Online Appendix introduces an extension of the benchmark model with progressive taxation schemes following the estimations in the literature and shows that such more sophisticated tax regimes do not affect the qualitative results in this paper.

The rest of the parameters are calibrated jointly, though each of these is set targeting one directly related moment. Parameters $\rho, \sigma_{v}, \omega, v_{0}, A_{0}, \pi_{A}, \pi_{v}, \sigma_{A}, \sigma_{y}$, and $s$ are calibrated to match dispersion in hours of workers and entre preneurs, average hours worked by entrepreneurs and workers, number of entrepreneurs, persistence of income and hours for entrepreneurs, dispersion of income for entrepreneurs and workers, and the fraction of population switching from entrepreneurs to workers, respectively. Table 3 summarizes the values of parameters and the moments they target.

The two key features of the model are complementarities in the labor aggregation and the value of leisure volatility. Hence, it is important to highlight the identification of the parameters dictating the severity of these features, namely $\rho$ and $\sigma_{v}$, respec tively. Higher volatility in the value of leisure (larger $\sigma_{v}$ ) implies more dispersion in hours of workers and entrepreneurs. Meanwhile, higher complementarities (lower $\rho$ ) imply less flexibility, hence less dispersion, in workers' hours. Accordingly, $\sigma_{v}$ is set to match the hours dispersion (standard deviation in logs) for entrepreneurs, and $\rho$ is chosen to match the hours dispersion for workers, given $\sigma_{v}$ and the rest of the parameters. In other words, dispersion in entrepreneurs' hours is the discipline for the magnitude of the value of leisure shocks. Given this magnitude, $\rho$ is set to match the dispersion in workers' hours.

${ }^{11}$ Midrigan and $\mathrm{Xu}$ (2014) assume the span-of-control parameter to be equal to 0.85. Buera et al. (2011) calibrate it to be 0.79, whereas Cagetti and de Nardi (2006) use 0.88 
Table 3

Parameters.

\begin{tabular}{|c|c|c|}
\hline Parameter & Value & Basis \\
\hline \multicolumn{3}{|c|}{ Panel A: Literature or data directly } \\
\hline$\alpha$ & 0.330 & Cagetti and de Nardi (2006) \\
\hline$\delta$ & 0.020 & Cagetti and de Nardi (2006) \\
\hline$\beta$ & 0.983 & Cagetti and de Nardi (2006) \\
\hline$\gamma$ & 1.5 & Cagetti and de Nardi (2006) \\
\hline$B$ & 1 & Cagetti and de Nardi (2006) \\
\hline$\pi_{y}$ & 0.983 & Cagetti and de Nardi (2006) \\
\hline$\tau$ & 0.11 & Guner et al. (2014) \\
\hline$\phi$ & 2 & Inverse of labor supply elasticity \\
\hline$\eta$ & 0.504 & See text \\
\hline \multicolumn{3}{|c|}{ Panel B: Calibrated } \\
\hline$A_{0}$ & 2.627 & Fraction of entrepreneurs \\
\hline$\rho$ & 0.020 & Sd of log-hours (worker) \\
\hline$\sigma_{v}$ & 0.533 & Sd of log-hours (entr) \\
\hline$\sigma_{A}$ & 0.105 & Sd of log-income (entr) \\
\hline$\sigma_{y}$ & 0.043 & Sd of log-income (worker) \\
\hline$\pi_{v}$ & 0.641 & Persistence of log-hours (entr) \\
\hline$\pi_{A}$ & 0.786 & Persistence of log-income (entr) \\
\hline$v_{0}$ & 78 & Hours (worker, mean) \\
\hline$\omega$ & 0.557 & Hours (entr, mean) \\
\hline$s$ & 0.010 & Population switching to worker \\
\hline
\end{tabular}

The calibrated substitutability parameter $\rho$ is equal to 0.02 . This means that the model would overshoot (undershoot) the dispersion in workers' hours for a $\rho$ larger (smaller) than 0.02 , either keeping the rest of the parameters the same or recalibrating them to match their corresponding targets. The same holds for the variance of the value of leisure shocks, $\sigma_{v}$, which is calibrated to be 0.533 . As $\sigma_{v}$ is decreased (increased) around the benchmark calibration, the model would imply a dispersion in entrepreneurs' hours that is lower (higher) than the data. This is true not only if the rest of the parameters remain constant, but also when they are reset to keep fitting their targets.

Later, Section 6 will discuss the role of the model features by comparing the benchmark with two alternatives: one with no complementarities $(\rho=1)$ and one with no value of leisure volatility $\left(\sigma_{v}=0\right)$. Meanwhile, the Online Appendix includes a more thorough documentation of the sensitivity of their target moments to $\rho$ and $\sigma_{v}$.

\section{Results}

This section presents the main results. Table 4 compares the data and the model counterparts of the targeted moments in Panel A, and some untargeted ones in Panel B. The model fits the targeted moments completely. There are equally many entrepreneurs in the model as there are in the data, which is around 9 percent of the overall population. Entrepreneurs work slightly more than workers on average. The rate of occupational switch is around 0.5 percent. The model also matches the patterns of dispersion of income and working hours for both occupations. In particular, the cross sectional variation in income is around 95 percent higher for entrepreneurs than it is for workers; and for hours this margin is around 74 percent. Model implied persistence for income and hours for entrepreneurs also fits those in the data.

Next, I turn to the model's fit to the untargeted moments. The model can match the level differences in income between the two occupations closely. The average entrepreneur earns around 6 percent less than the average worker, both in the model and the data. Relative income of entrepreneurs is smaller, if one compares the medians instead of the means; both in the model and in the data. The median entrepreneur earns 14 percent less in the data, and 16 percent less in the model, than the median worker. The ratio of entrepreneurs earning more than the median worker is 36 percent in the data and 40 percent in the model. In addition, the model generates for workers an autocorrelation of log income at 0.81 and the autocorrelation of $\log$ hours at 0.66 , as they are in the data.

Evidence in Section 2 showed that the patterns of changes in hours in the data do not differ substantially if one looks at the hours controlled by productivity of an individual; and the corresponding discussion argued that this is because a sig nificant portion of the changes in hours are preference driven. (See Panel B of Fig. 1.) The next exercise computes in the model the mean absolute change in hours by agents with the same occupation two consecutive periods. Then it constructs the same change in residual hours, once controlled for hourly income. Table 4 shows that, both for entrepreneurs and workers, the differences in these means are very similar before and after controlling for the productivity. For entrepreneurs, the mean absolute changes in hours before and after controlling hours by hourly income are 0.053 and 0.051 , respectively. For workers these are equal to 0.030 for both measures. Importantly, these patterns resemble the corresponding feature in the data, where the mean changes in hours stay around 0.037 for entrepreneurs and 0.018 for workers after controlling by 
Table 4

Summary of results.

\begin{tabular}{|c|c|c|}
\hline Moment & Data & Model \\
\hline \multicolumn{3}{|l|}{ Panel A: Targeted } \\
\hline Fraction of entr & 0.088 & 0.088 \\
\hline Hours (entr, mean) & 0.243 & 0.242 \\
\hline Hours (worker, mean) & 0.239 & 0.239 \\
\hline Sd of log-inc (entr) & 0.658 & 0.655 \\
\hline Sd of log-inc (worker) & 0.336 & 0.336 \\
\hline Sd of log-hours (entr) & 0.405 & 0.404 \\
\hline Sd of log-hours (worker) & 0.234 & 0.232 \\
\hline Autocorr of log-inc (entr) & 0.746 & 0.746 \\
\hline Autocorr of log-hours (entr) & 0.694 & 0.694 \\
\hline Population switching to worker & 0.005 & 0.005 \\
\hline \multicolumn{3}{|l|}{ Panel B: Untargeted } \\
\hline Ratio of mean income (entr/worker) & 0.935 & 0.943 \\
\hline Ratio of median income (entr/worker) & 0.858 & 0.838 \\
\hline Autocorr of log-inc (worker) & 0.811 & 0.808 \\
\hline Autocorr of log-hours (worker) & 0.661 & 0.660 \\
\hline Population switching to entr & 0.004 & 0.005 \\
\hline Earning more than median worker (entr) & 0.364 & 0.404 \\
\hline Absolute change in hours (entr) & 0.037 & 0.053 \\
\hline Absolute change in hours (worker) & 0.018 & 0.030 \\
\hline Absolute change in hours (entr, res) & 0.037 & 0.051 \\
\hline Absolute change in hours (worker, res) & 0.018 & 0.030 \\
\hline
\end{tabular}

Note: The table documents the moments implied by the benchmark calibration. Panel A gives the comparison of the data and model in terms of the targeted moments. Panel B gives that for some important moments not targeted in calibration. "Earning mode than median worker" is the fraction of entrepreneurs with income above the median worker. "Absolute change in hours" is the average absolute change in the fraction of hours worked. Last two rows, denoted by "(res)", repeat this after controlling the fraction of hours worked by hourly income.
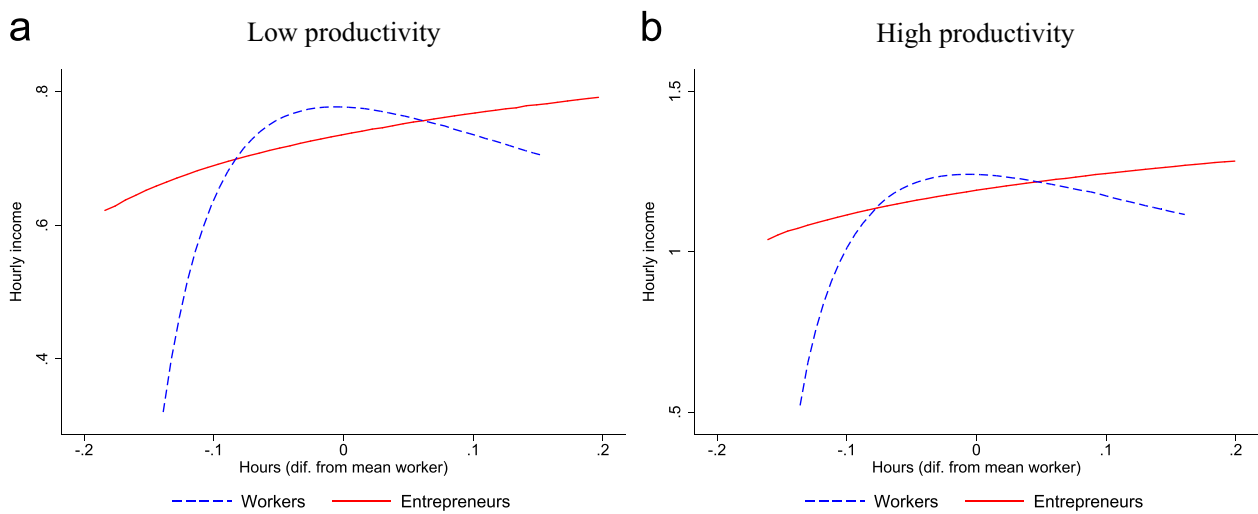

Fig. 3. Working hours and wages across productivity levels (model). Note: The initial levels of hourly income are normalized to have an overall average of 1 for workers. The left (right) figure uses workers with lower (higher) worker productivity and entrepreneurs with middle (higher) entrepreneurial productivity. Left (right) figure plots the Kernel-weighted local polynomial smoothing of hourly income across the levels of difference in hours from the mean worker with low (high) productivity. Confidence intervals are omitted as there is no further variation in hourly incomes given hours and productivity levels.

hourly income. In addition, the model replicates the distribution of changes in hours and residual hours controlled for hourly income very closely, and the Online Appendix includes the figures illustrating this. ${ }^{12}$

It is also worth using the model economy to illustrate the implications of complementarities in the labor aggregation on the wage hours relationship of workers. For this purpose, Fig. 3 plots the relationship between workers' hours (in difference to the mean worker in that productivity group) and their wage for each productivity level. In turn, this exercise is a replication of Fig. 2 using the model simulations instead of the data. The figure shows how the wages of workers in the model peak close to the mean hours in a fashion qualitatively similar to the pattern depicted for the data. Moreover, such peak does not exist for entrepreneurs. To show that, Fig. 3 separates the entrepreneurs with middle entrepreneurial ability (second ability grid out of

\footnotetext{
${ }^{12}$ As it is the case for the data, a KS test rejects that the model-implied distribution of changes in hours of workers is the same as that of workers at 99 percent confidence level, with a $D$-statistic of 0.22 . This is also true for the distributions of changes in hours conditional on hourly income, with a $D$-statistic of 0.20 .
} 
Table 5

Moments with alternative calibrations.

\begin{tabular}{|c|c|c|c|c|}
\hline Moment & Data & Benchmark & No comp. & Stable pref. \\
\hline \multicolumn{5}{|l|}{ Panel A: Targeted } \\
\hline Fraction of entr & 0.088 & 0.088 & 0.088 & 0.087 \\
\hline Hours (entr, mean) & 0.243 & 0.242 & 0.244 & 0.243 \\
\hline Hours (worker, mean) & 0.239 & 0.239 & 0.239 & 0.239 \\
\hline Sd of log-inc (entr) & 0.658 & 0.655 & 0.659 & 0.656 \\
\hline Sd of log-inc (worker) & 0.336 & 0.336 & 0.360 & 0.336 \\
\hline Sd of log-hours (entr) & 0.405 & 0.404 & 0.405 & 0.217 \\
\hline Sd of log-hours (worker) & 0.234 & 0.232 & 0.360 & 0.097 \\
\hline Autocorr of log-inc (entr) & 0.746 & 0.746 & 0.747 & 0.742 \\
\hline Autocorr of log-hours (entr) & 0.694 & 0.694 & 0.694 & 0.771 \\
\hline Population switching to worker & 0.005 & 0.005 & 0.005 & 0.005 \\
\hline \multicolumn{5}{|l|}{ Panel B: Untargeted } \\
\hline Ratio of mean income (e/w) & 0.935 & 0.943 & 1.192 & 0.901 \\
\hline Ratio of median income $(\mathrm{e} / \mathrm{w})$ & 0.858 & 0.838 & 1.000 & 0.526 \\
\hline Autocorr of log-inc (w) & 0.811 & 0.808 & 0.689 & 0.989 \\
\hline Autocorr of log-hours (w) & 0.661 & 0.660 & 0.688 & 0.997 \\
\hline Earn more than med. worker (e) & 0.364 & 0.404 & 0.501 & 0.368 \\
\hline Absolute change in hours (e) & 0.037 & 0.053 & 0.051 & 0.016 \\
\hline Absolute change in hours (w) & 0.018 & 0.030 & 0.043 & 0.000 \\
\hline
\end{tabular}

three in total) and those with the higher ability and repeat the similar exercise as for workers. It shows the corresponding patterns for entrepreneurs, particularly that the hump shaped pattern of hourly income is missing for entrepreneurs, as is true in the data. Instead, the hourly income of entrepreneurs has a monotone and increasing pattern in hours, as implied simply by the calibrated entrepreneurial weight, $\omega$, and the span of control, $\eta$, for their production function. ${ }^{13}$

The model performs well also in terms of the distributions of income and hours. Section 6 revisits the corresponding discussion with a comparison of the benchmark model's implications for important distributional moments with key alternative settings.

\section{Role and implications of the model features}

This section consists of two quantitative exercises that aim to discuss the role of two important features of the benchmark model. First exercise replicates the calibration exercise if the complementarities between workers' hours are assumed away (i.e. $\rho=1$ ). Second one studies the role of volatile value of leisure using a model that shuts down this aspect of uncertainty (i.e. $\sigma_{v}=0$ ).

\subsection{Complementarities in the labor aggregation}

Complementarities between the hours of workers in the labor aggregation is a novel feature of this paper. The objective here is to show the implications of the model if this feature is taken out, which means setting $\rho$ equal to 1 . In the benchmark exercise, the targeted moment to calibrate $\rho$ is the dispersion in workers' hours. Accordingly, the calibration strategy for this setup is to replicate the benchmark exercise with the exception of not targeting the dispersion in workers' hours. The main moments implied by this alternative are given in Table 5, and the summary of the calibrated parameters is deferred to the Online Appendix.

In this alternative, denoted as "No complementarities", the link between workers' hours disappears and their wages are constant across hours. (The Online Appendix includes a replication of Fig. 3 for this setting, illustrating how the hourly income changes with hours for both occupations.) This implies complete flexibility in salaried work, hence brings coun terfactually high dispersion in working hours for this group (by more than 50 percent). The model also worsens in its fit to the patterns of income and working hours for workers. First, the implied dispersion in income for workers, which is a targeted moment, is higher than the data counterpart even when shutting down the variation in the underlying worker ability completely. Second, the model performs poorly in replicating the observed persistence of income and hours, two moments that the benchmark matches very closely, also without targeting. Finally, Table 6 shows that this model performs worse than the benchmark in replicating the observed distributional features of income and hours for workers. Especially, the poor fit of the distribution of hours, which is of first order relevance to $\rho$, is substantial.

The case of perfect substitutability is a tool to show the role of flexibility related motives for entrepreneurship. By making the dispersion and changes in hours of workers larger than what they are in the data, this modification leaves

\footnotetext{
${ }^{13}$ Basically, having $\omega+\eta>1$ implies a positive relationship between hours and income of entrepreneurs given their productivity.
} 
Table 6

Inter-percentile ratios of income and hours.

\begin{tabular}{|c|c|c|c|c|}
\hline Percentile ratio & Data & Benchmark & No comp. & Stable pref. \\
\hline \multicolumn{5}{|c|}{ Panel A: Income distribution } \\
\hline \multicolumn{5}{|l|}{ Entrepreneurs } \\
\hline $50 / 25$ & 1.439 & 1.591 & 1.579 & 1.139 \\
\hline $75 / 25$ & 1.920 & 2.415 & 2.728 & 2.768 \\
\hline $90 / 75$ & 1.172 & 1.210 & 1.125 & 1.068 \\
\hline $95 / 75$ & 1.607 & 1.761 & 1.707 & 1.157 \\
\hline \multicolumn{5}{|l|}{ Workers } \\
\hline $50 / 25$ & 1.185 & 1.249 & 1.357 & 1.626 \\
\hline $75 / 25$ & 1.366 & 1.599 & 1.814 & 1.785 \\
\hline $90 / 75$ & 1.172 & 1.210 & 1.125 & 1.068 \\
\hline $95 / 75$ & 1.317 & 1.263 & 1.398 & 1.092 \\
\hline \multicolumn{5}{|c|}{ Panel B: Hours distribution } \\
\hline \multicolumn{5}{|l|}{ Entrepreneurs } \\
\hline $50 / 25$ & 1.191 & 1.335 & 1.236 & 1.124 \\
\hline $75 / 25$ & 1.209 & 1.336 & 1.361 & 1.182 \\
\hline $90 / 75$ & 1.168 & 1.250 & 1.344 & 1.114 \\
\hline $95 / 75$ & 1.287 & 1.420 & 1.448 & 1.146 \\
\hline \multicolumn{5}{|l|}{ Workers } \\
\hline $50 / 25$ & 1.094 & 1.197 & 1.347 & 1.087 \\
\hline $75 / 25$ & 1.168 & 1.438 & 1.796 & 1.169 \\
\hline $90 / 75$ & 1.119 & 1.100 & 1.130 & 1.029 \\
\hline $95 / 75$ & 1.230 & 1.234 & 1.413 & 1.029 \\
\hline
\end{tabular}

productivity as the major determinant of entrepreneurial decision. Hence, relative income of entrepreneurs and the fraction earning more than the median worker is more than the benchmark and the data.

\subsection{Volatile value of leisure}

The next exercise studies the economy in which the value of leisure is uniform across individuals. There are two main aspects that the calibration for this alternative would differ from the benchmark. First, the persistence and the volatility of hours of entrepreneurs are not targeted in this alternative, as these are the targets of the benchmark calibration in setting the persistence and volatility parameters for the value of leisure. Second, with uniform value of leisure, the model underpredicts the dispersion for hours of workers, for any value of $\rho$. Hence, $\rho$ is set at 1 to enable this alternative generate the highest possible dispersion for workers' hours. In effect, this setting is a further deviation from the benchmark than the previous alternative, which has volatile value of leisure but lacks complementarities across hours.

Table 5 shows that this model, denoted as "Stable preferences", can only generate about half of the dispersion in working hours for both occupational groups, even though the dispersion in income is replicated exactly. It also does poorly on the persistence of income and hours for workers, and hours of entrepreneurs. In line with this, Table 6 shows that the per formance of this model in the distributional patterns is worse than both the benchmark and the "No complementarities" model. Overall, this exercise confirms the findings in studies of labor supply such as Erosa et al. (2016) regarding the importance of value of leisure shocks in generating the observed variation in working hours. Accordingly, the results point at the desire for flexibility in hours as a factor in individuals' labor supply decisions.

\subsection{Relevance for policy}

The features discussed above are new in the models of occupational choice and they create a link between entrepre neurship and various regulations, which we would not otherwise think of. Below are two examples as such: maximum hours restrictions and income taxes.

Maximum workweek: Restrictions on the workweek usually have two motives: sustaining a better work life balance and reducing unemployment. ${ }^{14}$ While the model in this paper is not built for unemployment analysis, it provides a good laboratory to study the effects of this policy on workers' trade off between working time and leisure. The first experiment studies the implications of introducing an upper bound on workers' hours that is equal to a level 40 percent higher than the average. Importantly, the policy change is not anticipated by the economy, and the computations capture the entire tran sition to the new steady state. ${ }^{15}$

\footnotetext{
${ }^{14}$ Recent examples of the tightening of these restrictions include Chile in 2005, France starting 2000, Japan throughout the last three decades, and S. Korea in 2004. For a survey of limits on the workweek, see Lee et al. (2007).

${ }^{15}$ Qualitative implications of hours restrictions are the same if we define the upper bound as 20,30 or 50 percent above the baseline mean for workers. However, for a ceiling below 20 percent above the baseline mean, fraction of entrepreneurs increase as a result of this policy in the benchmark.
} 
Panel A: Maximumum hours
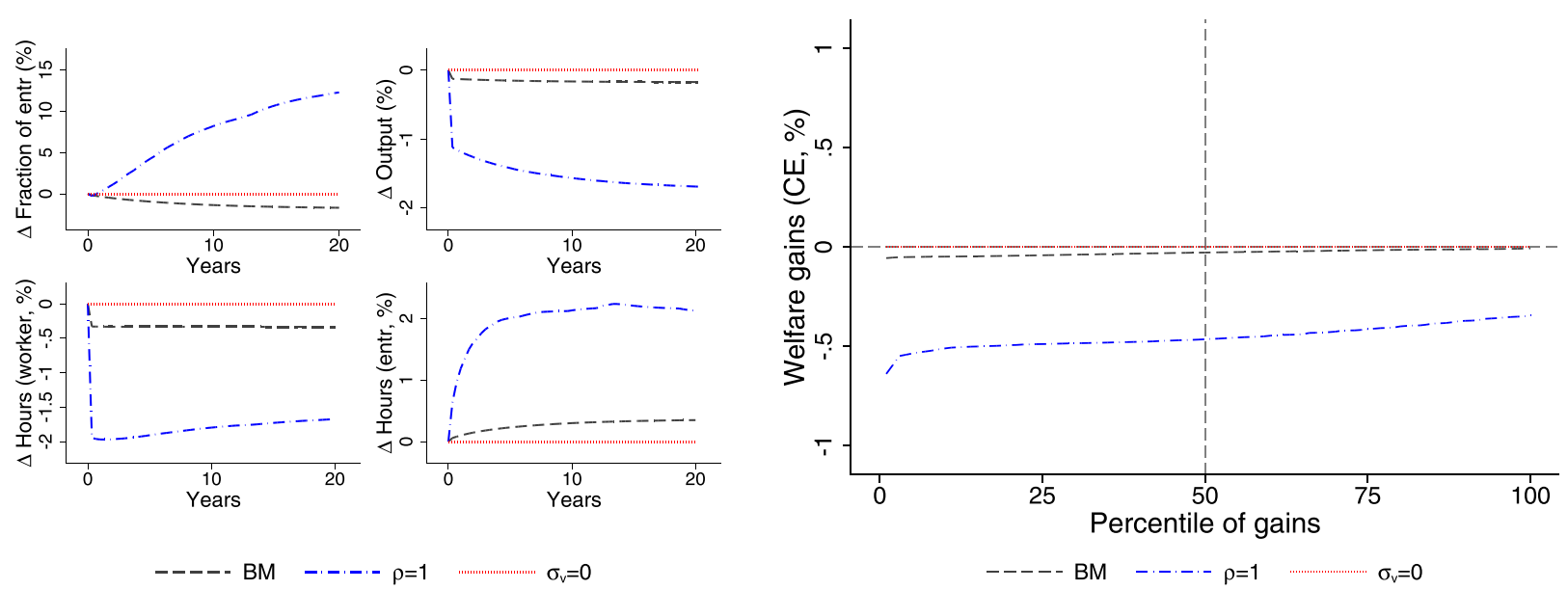

Panel B: Income tax
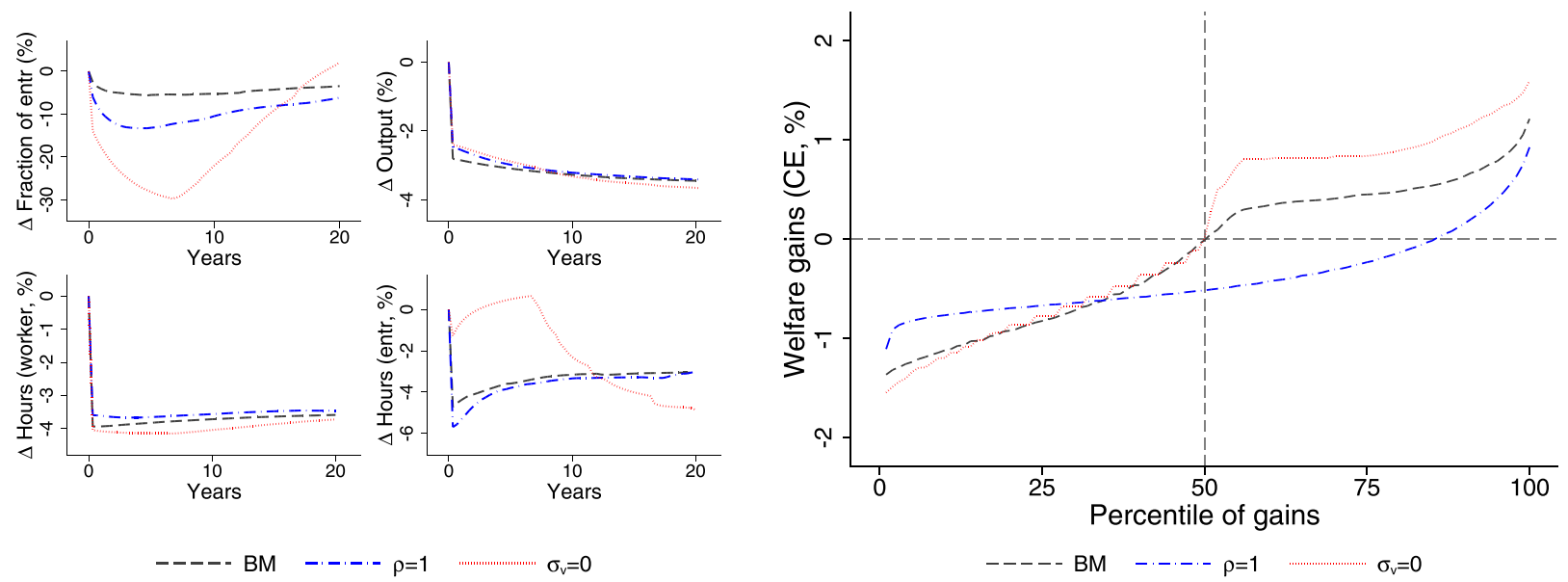

Fig. 4. Effects of imposing maximum hours (A) and income tax (B): transition and welfare. Note: Policy changes come as unanticipated shocks. " $\Delta$ Hours" gives the changes in average hours for each occupation group. Welfare gains are measured for each individual in the prereform steady state before the beginning of the transition.

Panel A of Fig. 4 shows that such a restriction in workers' hours actually does not lead to a decrease in the number of workers in the benchmark. Instead, there is a slight decrease in the number of entrepreneurs. There are many entrepreneurs that are in this occupation simply because their high value of leisure makes it too costly for them to work close to other workers. Imposing maximum hours for workers makes salaried work a more attractive option for these individuals. As a result, the number of entrepreneurs soon after the policy change is around 2 percent lower than the prereform level. In contrast, workers in the model with no complementarities $(\rho=1)$ have volatile preferences but do not have a flexibility concern prereform. Hence, restricting hours at the top makes workers with a low value of leisure worse off without helping others. This generates a 15 percent increase in the number of entrepreneurs in the steady state. In the second alternative $\left(\sigma_{v}=0\right)$, the variation in hours of workers is already low. Hence, the experimented upper bound does not affect the equilibrium outcomes, including the selection into entrepreneurship.

Fig. 4 also shows the limited reduction in the average hours by workers for the benchmark, contrary to the large drop predicted by the "No complementarities" model. For both models, the hours of entrepreneurs move in a fashion related to the movement in hours of workers. In particular, workers that are willing to work long hours become entrepreneurs, and this makes average hours worked by entrepreneurs increase. The output in the benchmark economy stays close to the prereform level. The model without complementarities predicts a large drop in output due to the fall in hours and the number of workers.

The welfare implications of the hours restrictions also vary across the modeling choices. In particular, Panel A of Fig. 4 shows that the median welfare loss following the announcement of the policy, in consumption equivalence units, is much 
smaller in the benchmark than it is in the alternative without complementarities. In the alternative without volatility in the value of leisure, the policy does not bind, hence there are no welfare effects.

Income taxation: Income taxation can have similar effects to workweek restrictions, to the extent that it leads to a reduction in working hours. The next example illustrates this by implementing a 10 percent additional labor earnings tax on everyone. $^{16,17}$

Panel B of Fig. 4 shows the negative effects of this experiment on workers' hours in all three models. This increases wages, and the number of entrepreneurs decreases in all models. While this latter effect is similar for the benchmark to the effects of the workweek restrictions, for the "No complementarities" model it contrasts with the large increase in the number of entrepreneurs implied by the previous policy. The difference of the latter model is that it has richer entrepre neurs, which gives an additional positive effect of the number of workers with stronger taxation.

The welfare gains from this change are qualitatively different from those implied by the workweek restrictions. Fig. 4 depicts that the median agent is roughly indifferent regarding this policy in the benchmark setting. In contrast, the "No complementarities" alternative implies welfare losses for the median agent, though the qualitative implications are similar in the alternative without volatility in the value of leisure to the benchmark.

\section{Conclusion}

Entrepreneurs in the US, on average, earn less than comparable workers. This paper shows that a model allowing for a flexible hours motive for entrepreneurship, disciplined to replicate the discrepancies in the patterns of working hours between entrepreneurs and workers, can generate this income differential with a margin similar to the one in the data.

The environment generalizes a standard entrepreneurship model in two ways. First, it features idiosyncratic shocks on the value of leisure. This creates a desire for flexible hours. Second, it introduces a labor aggregation technology in which workers' hours are complementary to each other. This brings a form of inflexibility to salaried work and creates an addi tional motive for being an entrepreneur. These help the model account for the low average income of entrepreneurs that is observed in the data. Importantly, the model performs well also in the implied income and hours distributions for both occupational groups.

\section{Acknowledgments}

I thank an anonymous referee and the editor for detailed comments. I am indebted to Rody Manuelli for his guidance in the preparation of this paper. I appreciate the suggestions from Limor Golan, Juan M. Sanchez, Ping Wang, Gaetano Antinolfi, Rui Castro, Andres Erosa, Barton Hamilton, George Levi Gayle, Nezih Guner, Fatih Guvenen, Alexander Monge Naranjo, Juan Pablo Nicolini, B. Ravikumar, Yongseok Shin, Jan Stuhler, Ija Trapeznikova, Felix Wellschmied and David Wiczer. I also benefited from the fruitful discussions at the Washington U. in St. Louis Graduate Students Conference (2013), Midwest Macro Meetings (Minnesota, 2013), Midwest Economics Association Meetings (Evanston, 2014), Spanish Economic Asso ciation Meetings (Mallorca, 2014), European Econometric Society Meetings (Madrid, 2014), REDg Workshop (Barcelona, 2015), and seminars at U. Carlos III, U. Amsterdam, the Bank of Canada and U. Exeter. I gratefully acknowledge the support from the Ministerio Economia y Competitividad (Spain), Maria de Maeztu grant (MDM 2014 0431), and from Comunidad de Madrid, MadEco CM (S2015/HUM 3444).

\section{Appendix A. Supplementary data}

Supplementary data associated with this article can be found in the online version at http://dx.doi.org/10.1016/j.jmoneco. 2017.01.002.

\section{References}

Aaronson, D., French, E., 2004. The effect of part-time work on wages: evidence from the social security rules. J. Labor Econ. 22 (2), $329-352$. Altonji, J.G., Paxson, C.H., 1988. Labor supply preferences, hours constraints, and hours-wage trade-offs. J. Labor Econ. 6 (2), $254-276$. Boheim, R., Taylor, M.P., 2004. Actual and preferred working hours. Br. J. Ind. Relat. 42 (1), 149-166.

Buera, F.J., Kaboski, J.P., Shin, Y., 2011. Finance and development: a tale of two sectors. Am. Econ. Rev. 101 (5), $1964-2002$.

Buera, F.J., Shin, Y., 2013. Financial frictions and the persistence of history: a quantitative exploration. J. Polit. Econ. 121 (2), $221-272$.

\footnotetext{
${ }^{16}$ Here, the tax rate on capital income remains at 11 percent to document more clearly the direct effects on the labor supply, without generating additional dynamics related to lower net returns from saving.

${ }^{17}$ Qualitative implications of income taxes are the same with tax rates of 20 and 30 percent, but the differences between the benchmark and the "No complementarities" model diminish for rates smaller than 5 percent.
} 
Cagetti, M., de Nardi, M., 2006. Entrepreneurship, frictions, and wealth. J. Polit. Econ. 114 (5), 835-870.

Dickens, W.T., Lundberg, S.J., 1993. Hours restrictions and labor supply. Int. Econ. Rev. 34 (1), 169-192.

Erosa, A., Fuster, L., Kambourov, G., 2016. Towards a micro-founded theory of aggregate labour supply. Rev. Econ. Stud. 83 (3), 1001-1039.

Guner, N., Kaygusuz, R., Ventura, G., 2014. Income taxation of u.s. households: facts and parametric estimates. Rev. Econ. Dyn. 17 (4), $559-581$.

Hamilton, B.H., 2000. Does entrepreneurship pay? An empirical analysis of the returns to self-employment. J. Polit. Econ. 108 (3), 604-631.

Hurst, E., Pugsley, B.W., 2011. What do small businesses do? Brook. Pap. Econ. Act. 43 (2 (Fall)), 73-142.

Kopecky, K., Suen, R., 2010. Finite state Markov-chain approximations to highly persistent processes. Rev. Econ. Dyn. 13 (3), $701-714$.

Lee, S., McCann, D., Messenger, J., 2007. Working Time Around the World: Trends in Working Hours, Laws and Policies in a Global Comparative Perspective. Routledge Studies in the Modern World Economy. Routledge LO, Geneva.

Lucas, R.E., 1978. On the size distribution of business firms. Bell J. Econ. 9 (2), 508-523.

Midrigan, V., Xu, D.Y., 2014. Finance and misallocation: evidence from plant-level data. Am. Econ. Rev. 104 (2), 422-458.

Pugsley, B., 2011. Selection and the Role of Small Business Owners in Firm Dynamics. Working Paper.

Rogerson, R., 2011. Individual and aggregate labor supply with coordinated working times. J. Money Credit Bank. 43, 7-37.

Stewart, M.B., Swaffield, J.K., 1997. Constraints on the desired hours of work of British men. Econ. J. 107 (441), 520-535. 